\title{
THE NOVEMBER MEETING IN CORAL GABLES
}

The five hundred fortieth meeting of the American Mathematical Society was held at the University of Miami in Coral Gables, Florida, on Friday and Saturday, November 29-30. About 80 persons registered, including 65 members of the Society.

By invitation of the Committee to Select Hour Speakers for Southeastern Sectional Meetings, there were two hour addresses. Professor Hans Rohrbach of the University of Mainz (visiting Professor at the University of North Carolina) spoke Friday evening on Mathematical methods of ciphering and deciphering, and Professor A. H. Clifford of Newcomb College, Tulane University, spoke Saturday morning on Totally ordered commutative semigroups. Professors Alfred Brauer and D. D. Miller presided at these sessions.

There were four sessions for contributed papers, Professor Gerald Huff, Donald Austin, Hans Rohrbach and J. H. Roberts presiding. Papers with abstract numbers 540-2, 540-21, 540-25, 540-27 and 540-28 were presented by title. Numbers 540-9, 540-13, 540-22 and 540-30 were presented, respectively, by A. T. Brauer, J. E. Maxfield, M. L. Curtis, and Naoki Kimura. Mr. Hunter was introduced by Professor R. J. Koch, Mr. Loeb by Dr. A. A. Goldstein, and Mr. Glasser by Professor Wayman Strother. Abstracts of the contributed papers will appear in the February and April issues of Notices of the American Mathematical Society.

JOHN H. RoBerTs, Associate Secretary 